\title{
Demographic, biological and dietary characteristics associated with endometriosis in a group of Sri Lankan women
}

\author{
Nalinda Silva ${ }^{1}$, Hemantha Senanayake ${ }^{2}$, Roshini Peiris-John ${ }^{1,4}$, Rajitha Wickremasinghe ${ }^{3}$ \\ Sri Lanka Journal of Obstetrics and Gynaecology 2011; 33: 91-97
}

\begin{abstract}
Objective: To identify demographic, biological and dietary factors associated with endometriosis in a group of Sri Lankan women.

Methods: A case-control study was conducted at two tertiary care hospitals. Women with endometriosis $(n=150)$ were compared with age-matched controls $(n=150)$ with no evidence of endometriosis, both confirmed by laparoscopy or laparotomy. Data were collected using an interviewer-administered questionnaire and a food frequency questionnaire. Means were compared using paired t-tests and chi square tests and odds ratios (OR) were used to determine associations between dichotomous variables. Conditional logistic regression analysis was done to adjust for potential confounding variables.
\end{abstract}

Results: The ethnic distribution, age at menarche, average length of the menstrual cycle and body mass index were similar in the two groups. The mean (+SD) duration of menstruation in the cases (4.11 \pm 0.11 days) was significantly higher than in the controls $(3.47 \pm 0.16$ days, $\mathrm{p}=0.01)$. Endometriosis was commoner among those with regular menstrual cycles $(\mathrm{OR}=3.108 ; 95 \%$ $\mathrm{CI}=1.473-9.627)$ and those having an education above Advanced Level (OR=1.729; 95\% $\mathrm{CI}=1.041-2.87)$. None of the food items was significantly associated with endometriosis. The risk of endometriosis was 2.084 times greater among those with an education above Advanced Level as compared to those having an education below Advanced Level $(p=0.021)$ after adjusting for confounding factors.

\footnotetext{
${ }^{1}$ Faculty of Medical Sciences, University of Sri Jayewardenepura, Sri Lanka.

${ }^{2}$ Faculty of Medicine, University of Colombo, Sri Lanka.

${ }^{3}$ Faculty of Medicine, University of Kelaniya, Sri Lanka.

${ }^{4}$ Section of Epidemiology and Biostatistics, School of Population Health, Faculty of Medical and Health Sciences, University of Auckland, New Zealand.

Correspondence: Nalinda Silva

E-mail:yasanga78@yahoo.com
}

Conclusion: Among Sri Lankan women, endometriosis is commoner among those who are more educated.

Key words: Endometriosis, demography, dysmenorrhea, education level, food frequency questionnaire.

\section{Introduction}

Endometriosis is an estrogen dependent disease that affects an estimated 6-10\% of females in the reproductive age group ${ }^{1}$. Among subfertile women, 25 to $50 \%$ have laparoscopic evidence of endometriosis ${ }^{2}$. Recently, an increase in the incidence of surgically diagnosed endometriosis has been noted in some countries $^{3}$. Patients ${ }^{4,5}$ and health care systems $s^{6,7}$ worldwide, are burdened by this disease in terms of morbidity and economic costs. In 2002 alone, the estimated cost of diagnosing and treating endometriosis in the United States of America (USA) was USD 22 billion ${ }^{1}$.

Despite extensive research, the etiology of endometriosis remains elusive. The chronic course and severity of this disease are defined by the persistence of the ectopic tissue with concomitant inflammation ${ }^{8}$. The etiological factors that promote the survival of ectopic tissue have been extensively investigated. These can be broadly categorized as factors that blunt the immune response in the pelvic cavity, factors that promote adherence or angiogenesis, pro-inflammatory substances and the estrogenic compounds that promote survival of the tissues ${ }^{8}$.

The use of patient characteristics to diagnose endometriosis instead of the standard surgical procedures has been tested previously ${ }^{9,10}$. Associations with potential risk factors have been used to predict the recurrence of ovarian endometriosis ${ }^{11}$. Although endometriosis is a benign disease, it shares some traits with malignancy ${ }^{8}$ and has been linked with ovarian cancer ${ }^{12}$. Epidemiological surveys are also instrumental in determining modifiable risk factors which once translated into lifestyle changes help to prevent the onset or deter the progression of disease. This has been shown to be successful in research related to breast cancer ${ }^{13}$. 
There are reports on demographic ${ }^{14}$, menstrual $^{15}$, biological ${ }^{16}$, dietary ${ }^{17,18}$ and life style ${ }^{14}$ characteristics that are linked to endometriosis. Some studies have shown that Asian women are at a higher risk of developing endometriosis ${ }^{19,20}$ which is postulated to be due to genetic polymorphisms that have been described $^{21,22}$. Some risk factors are common in studies done in different countries ${ }^{23}$. Modifiable risk factors of endometriosis such as dietary factors ${ }^{24}$, environmental exposures ${ }^{25,26}$, body size and figure ${ }^{27}$ have also been investigated. The consumption of soya based foods has been implicated as an etiological factor as soya contains phytoestrogens viz. genistein and daidzein ${ }^{25}$.

Data on endometriosis in Sri Lankan women are sparse. The exact prevalence of endometriosis remains unclear but a hospital based study conducted among subfertile women indicates that the figures are comparable to that from other countries with high prevalence $^{28}$. Demographic and menstrual characteristics of Sri Lankan women with endometriosis are seldom mentioned in medical literature.

This study was conducted to identify the demographic, biological and dietary characteristics associated with endometriosis in a group of Sri Lankan women.

\section{Materials and methods}

A hospital based case control study was conducted between June 2008 and September 2010 at the Professorial Gynaecology Unit of the National Hospital of Sri Lanka and Ward 8 of the De Zoysa Maternity Hospital, Colombo, Sri Lanka.

Three hundred women in the reproductive age (15 to 49 years) who were admitted to the above units for elective laparoscopy or laparotomy for diagnostic and/or treatment purposes constituted the study population. Indications for laparoscopy or laparotomy were subfertility, dysmenorrhoea, chronic pelvic pain and detection of an ovarian mass. Patients who underwent laparoscopy or laparotomy for the first time as well as those who had follow up surgery were recruited into the study.

A case was defined as a woman in the reproductive age group who has a confirmed diagnosis of endometriosis on laparoscopy or laparotomy. This included 150 patients who were already diagnosed with endometriosis or were diagnosed for the first time.

One hundred and fifty age matched women in whom endometriosis was excluded by laparoscopy or laparotomy were recruited as the control group.
Each control was \pm 4 years of the age of the corresponding case. A sample size of 150 women in each group is sufficient to detect an odds ratio of 2.5 with an alpha error of $5 \%$ and a power of $90 \%$, given the prevalence of exposure in the controls is $20 \%$.

Data were collected using a structured pre-tested interviewer-administered questionnaire which included questions on basic demographic characteristics, menstrual history, potential risk factors etc. A 45 item Food Frequency Questionnaire (FFQ) was used to gather information on regularly consumed food items and their frequency of consumption during a period of one year. This FFQ has already been validated in a Sri Lankan population ${ }^{29}$. The frequency of consumption of each food item was assessed against a scale of one to six as follows: one for "less than once a week", two for "once a week", three for "between twice and four times a week", four for "more than four times a week", five for "once per day" and six indicating a frequency of "more than once a day". The English version of the entire questionnaire was translated into Sinhala and the Sinhala translation was back translated into English by an independent person. The two English versions were compared and were found to be comparable. The questionnaire was pre-tested in a group of 10 patients who did not participate in the study at the Professorial Gynaecology Unit of the National Hospital prior to the study for comprehensibility.

SPSS version 13 for Windows and STATA were used for statistical analysis. Means were compared with paired T-tests. McNemar tests and odds ratios (OR) and their 95\% confidence intervals (CI) were calculated to test for associations between dichotomous variables. For analytical purposes, the FFQ data were categorized into two; frequencies one to three were amalgamated into one group while frequencies four to six were amalgamated into another group. For each food item, comparisons were done between consuming a given food item less than and more than four times a week. Conditional logistic regression analyses were done adjust for potential confounding variables.

Informed written consent was obtained from all the participants prior to elective laparoscopy or laparotomy. Ethical clearance was obtained from the Ethics Committees of the Faculty of Medical Sciences, University of Sri Jayewardenepura and the National Hospital of Sri Lanka.

\section{Results}

The mean (+SD) ages of cases and controls were $33.2( \pm 5.4)$ and $32.7( \pm 5.4)$, respectively $(p=0.14)$. The demographic characteristics of the study participants 
are summarized in Table 1. The distribution of cases and controls were similar in ethnic composition, occupation and province of residence. Patients who had an education level above Advanced Level (A/L) had a higher risk of developing endometriosis as compared to controls (OR=1.729; 95\% CI=1.041-2.87). The mean body mass index in cases $23.60( \pm 3.87)$ $\mathrm{Kg} / \mathrm{m}^{2}$ was similar $(P=0.855)$ to controls $23.50( \pm 4.62)$ $\mathrm{Kg} / \mathrm{m}^{2}$.

Patients with endometriosis were more likely to have regular menstrual cycles and longer duration of menstruation as compared to controls (Table 2). Age at menarche, length of cycle and passage of clots during menstruation were similar in cases and controls. A history of miscarriage, subfertility, nulliparity, and the use of hormonal contraceptives were not associated with endometriosis.

None of the food items considered in the FFQ was associated with the risk of endometriosis (Table 3). In the conditional logistic regression model, being educated more than Advanced Level was an independent risk factor of endometriosis after adjusting for regularity of cycles and duration of menstruation (Table 4).

Table 1. Demographic characteristics of the study population

\begin{tabular}{|c|c|c|c|}
\hline \multirow[t]{2}{*}{ Characteristic } & & of & OR $(95 \% \quad C I)$ \\
\hline & Cases $(n=150)$ & Controls $(n=150)$ & \\
\hline
\end{tabular}

\section{Ethnicity}

\begin{tabular}{|c|c|c|c|}
\hline Sinhalese & 139 (93.1) & $140(93.8)$ & $0.992(0.361-2.728)^{\S}$ \\
\hline Tamil & $5 \quad(3.1)$ & $5 \quad(3.1)$ & \\
\hline Muslim & $4 \quad(2.3)$ & $2 \quad(1.5)$ & \\
\hline Other & $5 \quad(3.1)$ & $0 \quad(0)$ & \\
\hline
\end{tabular}

\section{Education Level}

Below $\mathrm{A} / \mathrm{L}^{\dagger}$

Above $\mathrm{A} / \mathrm{L}^{\dagger}$

$$
\begin{array}{r}
50(33.0) \\
100(67.0)
\end{array}
$$

\section{Occupation}

$$
\begin{aligned}
& \text { House wife } \\
& \text { Employed }
\end{aligned}
$$

\section{Province of residence}

\begin{tabular}{lr} 
Western & 58 (38.6) \\
Other & $92(61.4)$ \\
\hline & \\
& ${ }^{\dagger}$ A/L- Advanced Level \\
& ` Based on McNemar Test \\
& \& Comparing Sinhala with all other ethnic groups
\end{tabular}

$\begin{array}{ll}70(46.9) & 0.710(0.524-1.026) \\ 80(53.1) & 1.729(1.041-2.87) \\ & \\ 90(60.0) & 0.862(0.690-1.077) \\ 60(40.0) & 1.202(0.913-1.582)\end{array}$

$0.628(0.383-1.031)$

$75(50.0)$ 
Table 2. Menstrual and gynaecological characteristics of study population

\begin{tabular}{|c|c|c|c|c|}
\hline Characteristic & Cases $(n=150)$ & Controls $(n=150)$ & $\begin{array}{l}\text { Odds ratio } \\
(95 \% \mathrm{CI})\end{array}$ & P value \\
\hline Mean $( \pm S D)$ age at menarche (years) & $12.94( \pm 1.53)$ & $12.84( \pm 1.64)$ & & $0.637^{\dagger}$ \\
\hline Mean $( \pm S D)$ length of cycle (days) & $28.33( \pm 2.01)$ & $28.53( \pm 2.17)$ & & $0.488^{\dagger}$ \\
\hline $\begin{array}{l}\text { Mean }( \pm S D) \text { duration of } \\
\text { menstruation (days) }\end{array}$ & $4.01( \pm 0.1)$ & $3.47( \pm 0.16)$ & & $0.043^{\dagger}$ \\
\hline n (\%) with regular cycles & $143(95.4)$ & $125(83.7)$ & $\begin{array}{c}3.108 \\
(1.473-9.627)\end{array}$ & $0.012^{\ddagger}$ \\
\hline $\begin{array}{l}\mathrm{n}(\%) \text { with passage of clots in } \\
\text { menstruation }\end{array}$ & $42(27.6)$ & $35(23.6)$ & $\begin{array}{c}1.234 \\
(0.683-2.229)\end{array}$ & $0.296^{\ddagger}$ \\
\hline $\mathrm{n}(\%)$ with a history of subfertility & $115(76.9)$ & $96(64.1)$ & $\begin{array}{c}1.392 \\
(0.992-1.894)\end{array}$ & $0.063^{\ddagger}$ \\
\hline n (\%) of nulliparous women & $50(33.1)$ & $49(32.8)$ & $\begin{array}{c}1.012 \\
(0.602-1.701)\end{array}$ & $1.000^{\ddagger}$ \\
\hline $\mathrm{n}(\%)$ with a history of miscarriages & $17(11.5)$ & $29(19.7)$ & $\begin{array}{c}0.532 \\
(0.266-1.065)\end{array}$ & $0.110^{\ddagger}$ \\
\hline n (\%) on hormonal contraceptives & $25(16.5)$ & $26(17.2)$ & $\begin{array}{c}1.247 \\
(0.956-1.626)\end{array}$ & $1.000^{\ddagger}$ \\
\hline
\end{tabular}

$\dagger \mathrm{p}$-value based on paired t-test

$\ddagger \mathrm{p}$-value based on McNemars Test

Table 3. Association between selected food items and endometriosis

\begin{tabular}{|c|c|c|c|c|}
\hline Food item & Odds ratio & $(95 \% C I)^{\dagger}$ & Pearson chi ${ }^{2}$ & $P$ value \\
\hline Green leaves & 1.254 & $(0.748-2.101)$ & 0.739 & 0.390 \\
\hline Green leafy vegetables & 1.059 & $(0.626-1.792)$ & 0.046 & 0.830 \\
\hline Root vegetables & 1.467 & $(0.859-2.506)$ & 1.982 & 0159 \\
\hline Full cream milk & 1.280 & $(0.719-2.281)$ & 0.706 & 0.401 \\
\hline Dairy products & 1.224 & $(0.585-2.564)$ & 0.288 & 0.591 \\
\hline Margarine & 1.009 & $(0.343-2.974)$ & 1.000 & 0.987 \\
\hline Coconut milk & 0.564 & $(0.279-1.140)$ & 2.588 & 0.108 \\
\hline Red rice & 0.951 & $(0.556-1.625)$ & 0.034 & 0.853 \\
\hline White rice & 0.60 & $(0.349-1.029)$ & 3.463 & 0.063 \\
\hline Wheat flour & 0.619 & $(0.257-1.492)$ & 1.159 & 0.282 \\
\hline Meat & 1.370 & $(0.46-4.081)$ & 0.323 & 0.570 \\
\hline Sea foods & 1.170 & $(0.699-1.960)$ & 0.356 & 0.551 \\
\hline Soya products & 1.010 & $(0.434-2.350)$ & 1.000 & 0.982 \\
\hline Wheat flour products & 0.619 & $(0.257-1.492)$ & 1.159 & 0.282 \\
\hline
\end{tabular}

${ }^{\dagger} \mathrm{OR}(95 \% \mathrm{CI})$ for consumption of a given food item more than four times a week vs less than 4 times a week. 
Table 4. Summary of conditional logistic regression analysis

\begin{tabular}{lcccc}
\hline Variable & Coefficient & Standard error & P value & $\begin{array}{c}\text { Adjusted OR } \\
(95 \% \text { CI })\end{array}$ \\
\hline Education level above A/L ${ }^{\dagger}$ & 0.734 & 0.317 & 0.021 & 2.084 \\
Regular cycles & & & & $(1.119-3.88)$ \\
Bleeding duration & 1.681 & 1.150 & 0.144 & 5.372 \\
& & & & $(0.563-51.227)$ \\
& 0.195 & 0.116 & 0.093 & 1.215 \\
\hline
\end{tabular}

\footnotetext{
${ }^{\dagger}$ Reference group is those educated below Advanced Level (A/L)

${ }^{\ddagger}$ Reference group is those with irregular cycles

${ }^{\S}$ Reference group is those with bleeding duration of less than 4.01 days
}

\section{Discussion}

Education beyond advanced level is positively associated with endometriosis in the group of Sri Lankan women investigated in this study. Patients with endometriosis and their age-matched controls had similar demographic, menstrual and dietary characteristics.

Findings of this study are comparable to studies done elsewhere. Attainment of a higher level of education, a potential proxy for socio-economic status, has been associated with endometriosis in studies done in different parts of the world ${ }^{27,30,31}$. Endometriosis has been referred to as a "disease of the high social class" ${ }^{\prime 2}$. Higher education permits a woman to gain employment and pursue a career. In our data, a higher percentage of cases $(50.8 \%)$ compared to controls $(40 \%)$ were employed although this difference was not statistically significant. Being a career woman predisposes the individual to stress, both physical and psychological which are known to have ill effects on the reproductive and immune functions ${ }^{33}$. Some researchers have found that certain occupations are associated with a slightly increased risk of endometriosis $^{34}$. However, other possibilities have to be explored in interpreting this finding. The more educated are more likely to delay child bearing and be aware of the available treatment options to seek them ${ }^{32}$ which may have been reflected in our results.

Although ethnic disparities have been observed elsewhere ${ }^{19}$, there was no difference in the occurrence of endometriosis between the major ethnic groups in our sample. The majority of both cases and controls in this study as expected were Sinhalese. The few participants from other ethnicities may have masked any effect due to ethnicity, if it truly existed. With identification of new genetic polymorphisms ${ }^{35}$ the effect of ethnicity on the causation of endometriosis in the Sri Lankan population may be explored further.

Menstrual characteristics have been extensively scrutinized in studies related to endometriosis. In this study, women with endometriosis were more likely to have regular menstrual cycles and longer periods of menstruation as reported in other studies in bivariate analyses ${ }^{36,37}$. The retrograde transplantation theory is the widely accepted mechanism of endometriosis ${ }^{8}$. Regular cycles and longer periods of menstruation are known to predispose a person to retrograde menstruation and have been found to be associated with endometriosis ${ }^{15}$. Conflicting findings have also been reported in the literature in respect to menstrual features and endometriosis ${ }^{15}$. The value of menstrual characteristics in the non-invasive diagnosis of endometriosis has been emphasized ${ }^{9}$.

Similar to a study conducted in the USA, the cases and controls in this study also had comparable $\mathrm{BMIs}^{38}$. In other studies, it has been reported that endometriosis is associated with low body mass index ${ }^{14,16,27,39}$.

The role of dietary factors in the pathogenesis of endometriosis has been investigated previously. While substances like phytoestrogens are implicated in the aetiology of the disease, dietary characteristics are widely viewed as modifiable risk factors ${ }^{24}$. We explored the association between endometriosis and 
food items using a previously validated $\mathrm{FFQ}^{29}$. Although there is criticism of using simple recall as the method of measuring the number and frequency of food items, similar FFQs have been used in other countries $^{40}$. We did not identify any food item as a risk factor of endometriosis. This finding needs to be interpreted with caution given the relatively small sample size.

The use of hospital settings for risk factor assessment may not reflect in entirety the conditions in the general population ${ }^{41}$. Nevertheless, many of the studies that have investigated the risk factors of endometriosis have enrolled controls from among hospital patients as the exclusion of endometriosis too requires a surgical procedure ${ }^{31}$. Sixty one percent of the cases and $50 \%$ of the controls recruited from the two hospitals were from places outside the Western Province of Sri Lanka indicating a population fairly representative of the general population. The use of infertile women in studies on endometriosis has also been criticized as $25-50 \%$ of them are known to have endometriosis $^{2}$. In this study, a high proportion of cases $(76.9 \%)$ and controls $(64.1 \%)$ had a history of subfertility. In previous studies too a high proportion of subfertility has been noted among patients with endometriosis ${ }^{33}$. Researchers have in the past opted to use highly selective groups of controls to exclude selection and diagnosis biases ${ }^{14}$. In this study, controls were recruited among those who had no visual evidence of endometriosis. The two teaching hospitals in which the study was carried out are tertiary care settings, where probably patients with more severe forms of the disease are seen possibly giving rise to some form of selection bias. Demographic and menstrual characteristics have been observed to differ with increasing severity of endometriosis ${ }^{36}$.

In conclusion, patients with endometriosis investigated in this study were more educated than those who did not have the disease. No other demographic, biological and dietary characteristic investigated were found to be associated with endometriosis after controlling for level of education in this group of Sri Lankan women, probably due to the homogeneity of the Sri Lankan population in terms of cultural norms, customs and ethnic and genetic admixture resident in a small island country. We highlight the need for further investigation of this chronic disease which has considerable morbidity and associated health care costs.

\section{Acknowledgements}

We wish to acknowledge the staff at the Professorial Gynaecology Unit, National Hospital, Sri Lanka for the support in data collection. This study was supported by the University of Sri Jayewardenepura (grant ASP/6/Re/2008/06), National Coordinating Committee on Reproductive Health Research of Sri Lanka and by the University of Alabama at Birmingham International Training and Research in Environmental and Occupational Health Programme, Grant Number 5 D43 TW05750, from the National Institutes of Health-Fogarty International Center (NIH-FIC). The content is solely the responsibility of the authors and do not necessarily represent the official views of the NIH-FIC.

\section{References}

1. Giudice LC. Endometriosis. N Engl J Med 2010; 362: 2389-98.

2. Bulletti C, Coccia ME, Battistoni S, Borini A. Endometriosis and infertility. J Assist Reprod Genet 2010; 27: 441-7.

3. Gylfason JT, Kristjansson KA, Sverrisdottir G, Jonsdottir $\mathrm{K}$, Rafnsson V, Geirsson RT. Pelvic endometriosis diagnosed in an entire nation over 20 years. Am J Epidemiol 2010; 172(3): 237-43.

4. Markovic M, Manderson L, Warren N. Endurance and contest: women's narratives of endometriosis. Health (London) 2008; 12: 349-67.

5. Huntington A, Gilmour JA. A life shaped by pain: women and endometriosis. Journal of Clinical Nursing 2005; 14(9): 1124-32.

6. Gao X, Outley J, Botteman M, Spalding J, Simon JA, Pashos CL. Economic burden of endometriosis. Fertil Steril 2006; 86(6):1-12.

7. Nnoaham KE, Sivananthan S, Hummelshoj L, et al. Global study of women's health: a multi-centre study of the global impact of endometriosis. Hum Reprod 2010; 25(Suppl 1): i1 - i339.

8. Nap AW, Groothuis PG, Demir AY, Evers JLH, Dunselman GAJ. Pathogenesis of endometriosis. Best Pract Res Clin Obstet Gynaecol 2004; 18(2): 233-44.

9. Eskenazi B, Warner M, Bonsignore L, Olive D, Samuels S, Vercellini P. Validation study of nonsurgical diagnosis of endometriosis. Fertil Steril 2001; 76(5): 929-35.

10. Nnoaham KE, Sivananthan S, Hummelshoj L, et al. Multicentre studies of the global impact of endometriosis and the predictive value of associated symptoms. Journal of Endometriosis 2009; 1(1): 36-45.

11. Liu X, Yuan L, Shen F, Zhu Z, Jiang H, Guo S-W. Patterns of and risk factors for recurrence in women with ovarian endometriomas. Obstet Gynecol 2007; 109(6): 1411-20.

12. Vlahos NF, Kalampokas T, Fotiou S. Endometriosis and ovarian cancer: a review. Gynecol Endocrinol 2010; 26(3): 213-19.

13. Hellmann SS, Thygesen LC, Tolstrup JS, Grønbaek M. Modifiable risk factors and survival in women diagnosed with primary breast cancer: results from a prospective cohort study. Eur J Cancer Prev 2010; 19(5): 366-73. 
14. Missmer SA, Hankinson SE, Spiegelman D, Barbieri RL, Marshall LM, Hunter DJ. Incidence of laparoscopically confirmed endometriosis by demographic, anthropometric, and lifestyle factors. Am J Epidemiol 2004; 160: 784-96.

15. Treloar SA, Bell TA, Nagle CM, Purdie DM, Green AC. Early menstrual characteristics associated with subsequent diagnosis of endometriosis. Am J Obstet Gynecol 2010; 202: 534.e1-6.

16. Yi KW, Shin J-H, Park MS, Kim T, Kim SH, Hur J-Y. Association of body mass index with severity of endometriosis in Korean women. International Journal of Gynecology and Obstetrics 2009; 105: 39-42.

17. Parazzini F, Chiaffarino F, Surace M, et al. Selected food intake and risk of endometriosis. Hum Reprod 2004; 19(8): 1755-59.

18. Trabert B, Peters U, De-Roos AJ, Scholes D, Holt VL. Diet and risk of endometriosis in a population-based casecontrol study. Br J Nutr 2011; 105(3): 459-67.

19. Sangi-Haghpeykar H, Poindexter-III AN. Epidemiology of endometriosis among parous women. Obstet Gynecol 1995; 85(6): 1-10.

20. Arumugam K, Templeton AA. Endometriosis and race. Aust N Z J Obstet Gynaecol 1992; 32: 164-5.

21. Lakshmi KV, Shetty P, Vottam K, Govindhan S, Ahmad SN, Hasan Q. Tumour necrosis factor alpha - C850T polymorphism is significantly associated with endometriosis in Asian Indian women. Fertil Steril 2010; 94(2): 453-6.

22. Kim H, Park JH, Ku S-Y, Kim SH, Choi YM, Kim JG. Association between endometriosis and polymorphisms in insulin-like growth factors (IGFs) and IGF-I receptor genes in Korean women. Eur J Obstet Gynecol 2011;doi:10.1016/j.ejogrb.2010.12.018 (In press).

23. Kuohung W, Jones GL, Vitonis AF, et al. Characteristics of patients with endometriosis in the United States and the United Kingdom. Fertil Steril 2002; 78(4): 1-6.

24. Missmer SA, Chavarro JE, Malspeis S, et al. A prospective study of dietary fat consumption and endometriosis risk. Hum Reprod 2010; 25(6): 1528-35.

25. Foster WG, Agrawal SK. Environmental contaminants and dietary factors in endometriosis. Ann N Y Acad Sci 2002; 955: 213-29.

26. Heilier JF, Donnez J, Nackersd F, et al. Environmental and host-associated risk factors in endometriosis and deep endometriotic nodules: a matched case-control study. Environ Res 2007; 103: 121-9.

27. Hediger ML, Hartnett HJ, Louis GMB. Association of endometriosis with body size and figure. Fertil Steril 2005; 84(5): 1-9.

28. Sujaharan G, Marasinghe U. A study on the role of laparoscopy in female subfertility. Sri Lanka Journal of Obstetrics and Gynaecology 2005; 27(Supplement 1): 34

29. Arambepola C. (2004) Abdominal obesity and its association with selected risk factors of coronary heart disease in an adult population in the district of Colombo. Thesis (MD in Community Medicine). Postgraduate Institute of Medicine, University of Colombo, Colombo.

30. Hemmings R, Rivard Ml, Olive DL, et al. Evaluation of risk factors associated with endometriosis. Fertil Steril 2004; 81(6):1-9.

31. Signorello LB, Harlow BL, Cramer DW, Spiegelman D, Hill JA. Epidemiologic determinants of endometriosis: a hospital based case-control study. Ann Epidemiol 1997; 7: 267-74.

32. ViganòP, Parazzini F, Somigliana E, Vercellini P. Endometriosis: epidemiology and aetiological factors. Best Pract Res Clin Obstet Gynaecol 2004; 18(2): 177-200.

33. Holoch KJ, Lessey B. Endometriosis and infertility. Clin Obstet Gynecol 2010; 53(2): 429-438.

34. Marino JL, Holt VL, Chen C, Davis S. Lifetime occupational history and risk of endometriosis. Scandenavian Journal of Work Environment Health 2009; 35(3): 233-240.

35. Bischoff F, Simpson JL. Genetics of endometriosis: heritability and candidate genes. Best Pract Res Clin Obstet Gynaecol 2004; 18(2): 219-32.

36. Sinaii N, Plumb K, Cotton L, et al. Differences in characteristics among 1,000 women with endometriosis based on extent of disease. Fertil Steril 2008; 89(3): 538-45.

37. Vercellini P, De-Giorgi O, Aimi G. Menstrual characteristics in women with and without endometriosis. Obstet Gynecol 1997; 90(2): 264-68.

38. Templeman C, Marshall SF, Ursin G, et al. Adenomyosis and endometriosis in the California Teachers Study. Fertil Steril 2008; 90(2): 415-22.

39. Matalliotakis IM, Cakmak H, Fragouli YG, AGG, Mahutte NG, Arici A. Epidemiological characteristics in women with and without endometriosis in the Yale series. Arch Gynecol Obstet 2008; 277: 389-93.

40. Sirot V, Dumas C, Leblanc J-C, Margaritis I. Food and nutrient intakes of French frequent seafood consumers with regard to fish consumption recommendations: results from the CALIPSO study. Br J Nutr 2010; 16: 1-13.

41. Zondrvan KT, Cardon LR, Kennedy SH. What makes a good case-control study? Design issues for complex traits such as endometriosis. Hum Reprod 2002; 17(6): 1415-23. 